\title{
Las efemérides de San Fernando
}

\author{
OSWALDO SALAVERRY \\ Departamento de Medicina Preventiva y Salud Pública. Facultad de Medicina - UNMSM.
}

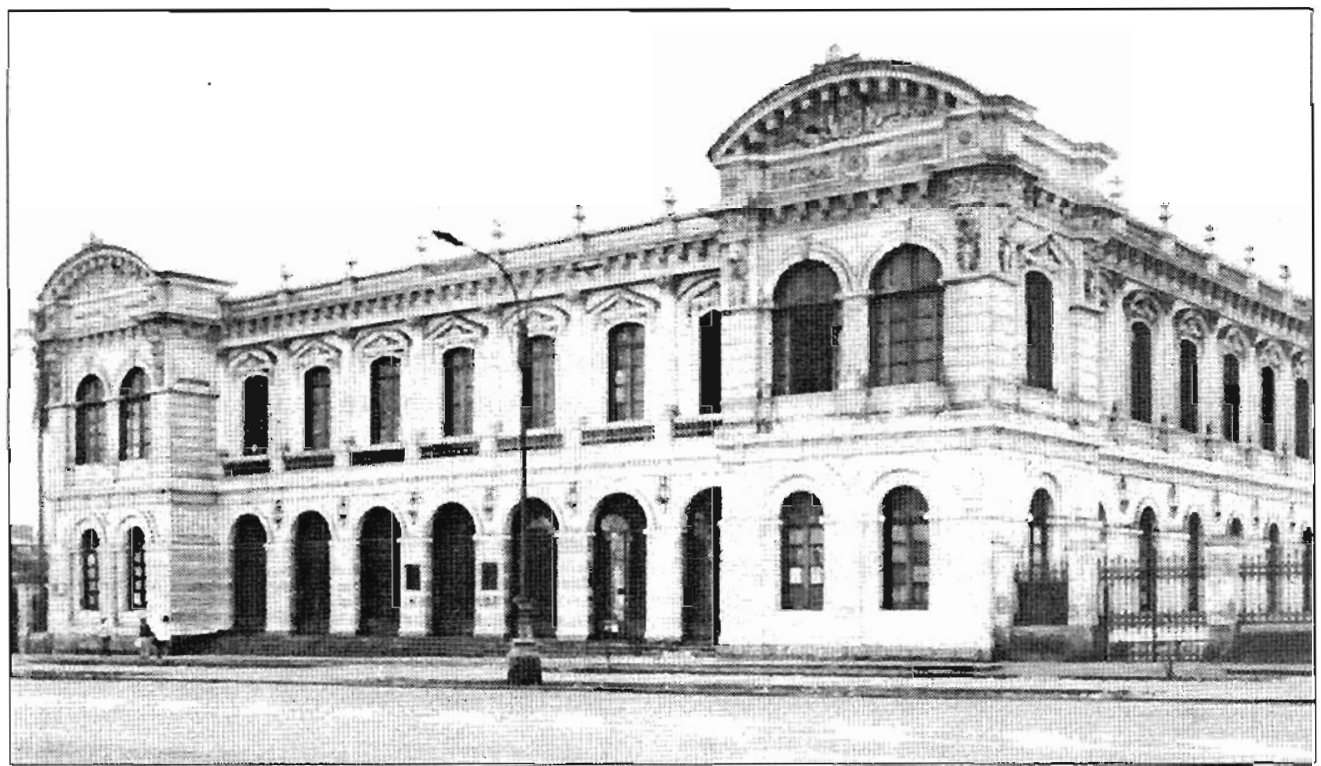

Frontis de la Facultad de Medicina de San Fernando - UNMSM.

La primera semana de octubre es tradicionalmente reconocida como la semana de la Medicina Peruana, con su efeméride principal, el cinco de octubre, que conmemora la muerte de Carrión, el estudiante símbolo de nuestra Escuela Médica. Probablemente envueltos en ese halo, pocos recuerdan celebrar el aniversario de la Facultad, el cual forzada o descuidadamente se considera que coincide con las mismas fechas. Un breve resumen de nuestra histo-

\section{Correspondencia:}

Dr. Oswaldo Salaverry García

Departamento de Medicina Preventiva y Salud Pública Facultad de Medicina - UNMSM

Av. Grau 755. Lima 1, Perí

E-mail:ossal@ummsm.edu.pe ria institucional nos permitirá identificar diferentes efemérides que debieran ser recordadas por nuestra Alma Mater, naturalmente sin disminuir el carácter icónico de la muerte de Carrión.

La enseñanza de la medicina en el Perú se inicia en la Universidad de San Marcos, y al menos estatutariamente muy tempranamente. En efecto, las primeras Constituciones de la Universidad, formuladas bajo el auspicio del Virrey Francisco de Toledo, y que marcaron la secularización del Estudio General, instituian dos Cátedras de Medicina: Prima y Vísperas, de las cuales se disponía que la primera se proveyera con una renta de 800 pesos, postergándose la dotación de la segunda. Se desconoce el motivo por el cual no se efectuó 
dotación alguna, por lo cual tampoco se designó Catedrático ni se leyeron lecciones durante el siglo XVI. Debimos esperar hasta inicios del siglo XVII para encontrar una confluencia de intereses del Cabildo y el Rector de San Marcos solicitando al Virrey, y por su intermedio a la Corona, que se provean cátedras de Medicina en la Universidad de Lima (').

El Conde de Chinchón fue quien, el 19 de noviembre de 1634 , ordenó la provisión de la Cátedra de Prima de Medicina, dotándola de seiscientos pesos y designando como su primer titular al Dr. Juan de la Vega, médico de su cámara. En el mismo año proveyó la Cátedra de Vísperas, que según su categoría, inferior a la de Prima, sólo contaría con una dotación de cuatrocientos pesos y estuvo a cargo del Dr. Jerónimo Andrés Rocha. Esta fecha de novienbre de 1634 es el más antiguo antecedente de la educación médica formal en el Perú, aunque no en América, pues ya para esa fecha existían Cátedras establecidas en la Universidad de México. Refiere Antonio de Suardo que la primera lección de Prima de Medicina se realizó el 17 de abril de 1635; sin embargo, aún faltaba la confirmación regia, la cual demoró hasta abril de 1638, con la real cédula aprobatoria de Felipe IV. Se conforma así, en nuestro más antiguo antecedente, una tríada de efemérides, la de la creación de la Cátedra, la de la primera lección y la de la formalización real. Esta complejidad nos seguirá acompañando en la determinación de los próximos hitos.

La educación médica a través de las cátedras de Prima y Vísperas, era de carácter escolástico, es decir, que se limitaba a la lectura de un texto por el catedrático, el cual luego pasaba a comentar eruditamente a otros autores que hubieran tratado el cema o materia. Los escasos libros, la ausencia de contacto con los cambios revolucionarios en la medicina renacentista y un ambiente general poco favorable a la investigación daban como resultado un médico con escasos recursos técnicos aunque con un florido verbo. Pasaron casi 30 años más antes que se instituyera, en 1660, la tercera cátedra del esquema clásico de la formación médica, la Cátedra de Método de Galeno; sin embargo, al igual que en el caso de las dos primeras, por falta de rentas para su dotación no fue sino hasta 1691 que se dictaron las primeras lecciones, con su primer catedrático, el Presbitero Francisco Vargas Machuca. En 1660 también se había considerado la erección de la cátedra de Anatomía, pero ésta tuvo que esperar hasta 1711 para ser dotada de rentas, siendo su primer catedrático el Dr. Joseph de Fontidueñas, el cual no llegó a desempeñar el cargo, siendo el segundo catedrático el Dr. Pedro López de los Godos el que, en 1723, dictaría las primeras lecciones. La aprobación real para la Cátedra de Anatomía llegaría sólo en 1752.

La enseñanza de la Medicina estaba formalmente completa con las cuatro cátedras aunque todas, incluyendo la de Anatomía, continuaban siendo escolásticas y por tanto rendían escasos frutos. Un reflejo de esta pcrcepción en la sociedad de la ćpoca es la obra del poeta Juan del Valle y Caviedes "Guerra Physica", la cual se suele citar por el espurio nombre de "Diente del Parnaso" y en la cual con agudeza y malicia presenta una descarnada imagen de la ignorancia del médico de la época. Otro indicador es la publicación por el médico italiano afincado en el Perú Federico Bottoni de un opúsculo denominado "Evidencia de la circulación de la sangre", en el cual luego de casi 100 años revisa el descubrimiento de Harvey. La Universidad, en este período, continuaba entregando grados doc-

1 En la sesión del Cabildo de Lima realizada el 16 de octubre de 1609 se lee: "En este cabildo se trato como esta ciudad tenia y tiene mucha necesidad que en la unibersidad della aya cátedras en donde se lea y enseñe medicina y cirugía... y que seria bien se suplicase al Excelentísimo señor bisorrey destos rreynos de parte deste cabildo se sirba de mandar que se lean y enseñen las dichas facultades en esta universidad para que tengan en que entretenerse muchos buenos entendimientos que ay en este rreyno y esta tierra goce del fruto dellos" (sic) 
torales, pero debe recordarse que el ejercicio médico dependía, en dicha época, de un examen rendido ante el Protomedicato, y que los estudios de la "Facultad Médica" eran necesarios, pero no suficientes.

Aunque es un período rico para el análisis, debemos avanzar en nuestro objeto de identificar las efemérides institucionales, lo cual nos lleva basta la inauguración del anfiteatro anatómico, que como es ampliamente conocido se realizó el 21 de noviembre de 1792, con el discurso de Unanue "Decadencia y restauración del Perú".

Lo que es menos conocido es que el proceso de creación del Anfiteatro respondía a una corriente iniciada en la Metrópoli, que buscaba fortalecer la Cirugía, y de la cual Unanue fue un intérprete. En efecto, una equivocada legislación para la formación de cirujanos latinos había conducido a la disminución de esta clase de cirujanos, proliferando en cambio los cirujanos romancistas, de menor formación y habilidades; lo que a su vez, en una época en que las divisiones entre cl médico y el cirujano eran tan marcadas, causaba en la práctica una desprotección de la población, y, más importante aún, desde el punto de vista del estado, una carencia para las fuerzas militares. Una reacción inicial fue la creación de Colegios de Medicina y Cirugía en España, el primero de los cuales fue el de Cádiz en 1748, que precisamente proveía de buenos médicos y cirujanos a la flota imperial. Se fundó luego el de Barcelona en 1734 y el de Madrid en 1787. Para los territorios de ultramar se favoreció la creación de anfiteatros anatómicos, donde los cirujanos pudieran obtener los conocimientos necesarios, pero siempre dentro del marco de las cátedras universitarias a las cuales estaban obligados a asistir.

En Lima, desde el 29 de julio de 1753, se había recibido la indicación de crear un anfiteatro en el Hospital de San Andrés, pero no se cumplió. En 1780, con mayor precisión, se encargo que el Protomédico y el catedrático de Anatomía, identificaran un ambiente adecuado en ese mismo hospital, pero al parecer no les pareció conveniente y recomendaron se utilizara los altos de la "loquería", lo cual tampoco se concretó. En el paso siguiente interviene Unanue, quien ya en posesión de la cátedra de Anatomía, consigue una dotación económica del Virrey Teodoro de Croix, pero que resultó insuficiente. Su sucesor Francisco de Taboada y Lemos, también a solicitud de Unanue, otorga 500 pesos más, con los que se concluye el edificio, que finalmente es inaugurado con presencia de la sociedad virreynal, fenómeno que debe también entenderse porque llegaban a Lima las noticias de las costumbres de la corte española, donde, en mayor contacto con el resto de Europa, se imponía la "moda" de asistir a disecciones anatómicas como parte del entusiasmo aristocrático por la ciencia. Los aristócratas limeños, siempre émulos de las tendencias metropolitanas, acudieron no sólo como espectadores, sino luego como alumnos, a las conferencias que de allí en adelante programó Unanue en el Anfiteatro, y de las cuales dan cuenta diversos medios de la época.

El siguiente paso en la definición de las efemérides nos conduce a la creación del Real Colegio de Medicina y Cirugía de San Fernando, el cual como se desprende del párrafo anterior representaba una tendencia nacida en la Metrópoli, y por tanto, sin disminuir el papel de Unanue, debemos reconocer que existía una buena disposición por factores de emulación, pero también porque correspondía a una política de estado que también se extendía a los territorios americanos. Refiere Unanue, que ya al erigirse el Anfiteatro había señalado la necesidad de un Colegio, pero es en diciembre de 1807, que eleva un memorial en que muy enjundiosamente muestra la necesidad y beneficios de dicho establecimiento. La buena disposición de las autoridades virreinales otorga en un primer momento el primer patio y las habitaciones adyacentes del Hospital Santa Ana, pero esto no agradó mucho al Mayordomo y a la Cofradía que sostenía el nosocomio, por lo que se decide edificarlo en un espacio vacío colindante entre los hospitales de Santa Ana y el San Andrés, en la actual plaza Italia. 
El inicio de la construcción fue en junio de 1808, y mucho antes que ésta terminara, el 13 de agosto de 1808, Unanue publica su conocido Quadro Sinóptico, plan de estudios que rompía con la tradición escolástica de las cuatro cátedras clásicas. Al parecer, las actividades lectivas en el nuevo local se iniciaron en enero de 1809 , cuando las obras aún estaban poco avanzadas, por lo que los escolares no podían aún quedarse a vivir (el colegio estaba programado como un internado) y debían escuchar clases y retirarse luego a unas habitaciones provisionales en la cercanía. La obra encargada a Matías Maestro se concluyó el 1 de octubre de 1811 , pero como ocurrió en anteriores oportunidades, la aprobación formal de la corona española demoró y en este caso es el propio Unanue, que en el intervalo ha sido electo como diputado ante las cortes de Cádiz, el que a su regreso trae la Real Cédula de creación del Colegio, que tiene por fecha el 9 de mayo de 1815. Nuevamente la dificultad de definir la fecha más representativa, esta vez para la creación del Colegio: la de su fundación o primera piedra en junio de 1808 , la de publicación del Quadro Sinóptico, en agosto de 1808, la del inicio de actividades en enero de 1809, la de culminación de las obras en octubre de $181 \mathrm{I}$, o la de formalización en mayo de 1815 .

La siguiente etapa en nuestra complicada identificación de efemérides es felizmente la más sencilla, y se refiere al Colegio de la Independencia. El 30 de julio de 1821 , y habiendo realizado el juramento republicano, se acordó de inmediato suprimir el incómodo título de "Real" a la denominación completa de la Institución y mantenerse como Colegio de Medicina y Cirugía de San Fernando. Algunos deben haber recordado que la apelación a San Fernando no se debió, en su momento, a algún apego especial a este miembro del santoral, sin mayor vinculación a la medicina, sino a la feliz coincidencia con Fernando de Abascal, y Fernando VII, Virrey y Emperador respectivanente, y ambos benefactores del Colegio, ya que nuy pronto, el 27 de agosto, el Ministro de Relaciones Exteriores comunicó que en mérito a los servicios prestados por los alumnos y maestros del colegio a la causa emancipadora se denominaría en adelante "Colegio de la Independencia". Añadimos una efeméride más, el 27 de agosto, en que adoptamos una nueva denominación y formalizamos un compromiso con la República.

Nos acercamos al período que con justicia es el más representativo: la creación de la Facultad de Medicina. Pero como se evidenciará, tampoco es simple determinar la fecha mas representativa para la efeméride de San Fernando. Es imprescindible en este momento describir sumarísimamente la relación entre el Protomedicato y la educación médica. Desde que la formación se realizaba a través de las cátedras, el resultado de haberlas cursado era la obtención de un grado, o bien de Licenciado en Medicina o el de Doctor. Pero ello no era suficiente para el ejercicio profesional, ya que esta autorización era de exclusiva competencia del Tribunal del Protomedicato, el cual decidía, confrontando los certificados y grados otorgados y sometiendo eventualmente a un examen, quienes podrían ejercer la profesión. Esta estructura, peculiar a España y sus dominios, se mantuvo independientemente del número de cátedras existentes o de los contenidos que en ellas se incluyeran. Inicialmente como una tradición, luego se formalizó que el Protomédico se convertiera también en Catedrático de Prima de Medicina, con lo cual la coordinación estaba asegurada.

Al crearse el Real Colegio de Medicina y Cirugía de San Fernando, la situación no se simplificó, sino que por el contrario sc complicó, pues al menos formalmente, el Colegio mantenía vinculación con la Universidad; si bien era el Colegio el que usufructuaba la dotación de sus cátedras, éstas aún tenían la denominación original de cátedras. El Colegio tomaba exámenes de las asignaturas, pero erá finalunente la Universidad la que otorgaba los grados, siguiendo el trámite y ceremonial tradicional. Luego de esto, se mantenía la evaluación por el Tribunal para el ejercicio profesional. Al iniciarse la República, y con ella el cuestionamiento de instituciones con fueros privativos, se hizo evidente que, al menos en 
la licencia de ejercicio no tenía sentido mantener a) Tribunal y en cambio debía fortalecerse el Colegio y sus "Facultades" $\left({ }^{2}\right)$.

En el proceso de creación de la Facultad de Medicina confluyeron varios procesos, uno de ellos es la sistematización de la educación, plasmada a través de sucesivos reglamentos, que incluyó a las Universidades, Colegios y Escuelas. El segundo es la aún incipiente pero ya evidente percepción por los legisladores de una particularidad en la educación médica, que ameritaba un tratamiento diferenciado con otras ramas del conocimiento. Correspondió al primer proceso la abolición del Tribunal del Protomedicalo, ya que como se indicaba en la norma "no pueden dejar de ser infructuosos los mejores reglamentos de enseñanza, si la calificación de suficiencia de los estudiantes no se hace por medio de exámenes severos y rigurosos prestados ance un cuerpo de prolicsores establecidos con este principal objeto." El segundo proceso también se puede evidenciar en el mismo rexto que más adelante dice: “... el protomedicato general carece en el díd de las facultades judiciales que eran las principales de su institución, y no llena con la organización que le dan las leyes, de un modo satisfactorio, el objeto de perfeccionar la instrucción pública en uno de los ramos más importantes para el bienestar y prosperidad de las naciones."

El 30 de diciembre de 1848, Ramón Castilla abolió el Tribunal del Protomedicato y formó en su reemplazó la "Junta Directiva de la Facultad de Medicina", la cual, pese a su denominación, no se refiere a la Facultad de Medicina como una institución sino a la "disciplina" médica. Su composición, con tres de los Catedráticos de San Marcos, el Rector del Colegio y tres profesores de asignaturas del Colegio de la Independencia, evidenciaba ya una inclinación a darle mayores funciones al Colegio y a integrarlo a San Marcos. El Reglamento General de Instrucción Pública del 14 de junio de 1850 , y luego el del 7 de abril de 1855 establecen claramente que las universidades tienen una estructura facultativa, y que San Marcos tiene una Facultad de Medicina, por lo que sólo resta que se formalice la creación, la desaparición del Colegio y la formación de la nueva facultad, lo que ocurre con la promulgación del "Reglamento Orgánico para la Facultad de Medicina de la Universidad de Lima" el 9 de septiembre de 1856 . En esa misma fecha se designa como primer Decano a Cayetano Heredia y se indica toda la plana docente. La instalación de la Junta de catedráticos ocurrió el 1 de octubre de 1856, como se puede comprobar en el $1^{\circ}$ libro de actas que obra en el Museo de la Facultad. Nuevamente el dilema de la efemérides: la fecha de la fundación formal o de la instalación de la Junta.

En 1956, al celebrarse el centenario de la Facultad de Medicina, la decisión fue clara, como se evidencia en el "Programa Conmemorativo" que abarca del 9 al 15 de sepciembre, y claro está que en ese año ya se conmemoraba la muerte de Carrión.

¿Qué es lo que ha sucedido en el intervalo? ¿Cuáles son las razones por las que la más antigua Facultad de Medicina del país y continuidad institucional con el Colegio de la Independencia y las cátedras coloniales, ha perdido su memoria histórica y ha dejado de celebrar sus cfemérides e incluso su aniversario de fundación? Es el tipo de pregunta que parece simple, pero tiene una respuesta compleja. Son varios factores, uno de ellos sin duda es la progresiva concentración en la figura de Carrión como arquetipo de valores e icono institucional, que por extensión se ha diseminado a la profesión en general; pero también está presente la sombra

\footnotetext{
${ }^{2}$ Es frecuente la confusión con la acepción de la palabra "facultad" en el siglo XVII y XVIII, pues se la utilizaba como "ciencia o arte" y no como institución que reúne a los cultivadores de una determinada parcela del conocimicnto. Asi, cuando con frecuencia se lec referencias a la Facultad de Medicina, se refierc a la Medicina como disciplina.
} 
de la renuncia docente de 1961 y el período inmediato de reconstrucción y reorganización no sólo material sino conceptual. La presencia relevante de los estudiantes, por demás muy fructífera en los años inmediato posteriores, orientó la imagen hacia un estudiante-símbolo, hacia un subyacente individualismo heroico y nos alejó de una imagen, tal vez menos gloriosa de una colectividad unida por el cultivo de la Medicina y que tiene efemérides no tan gloriosas pero sí representativas de hitos de construcción colectiva, de puntos de inflexión de procesos. Sin duda, hasta de una simple discriminación de efemérides se puede complejizar a las frecuentemente ocultas razones que nos conducen a una u otra decisión, pero en las cercanías de la Semana de la Medicina deberíamos plantearnos fortalecer nuestra conciencia institucional, vol- viendo de vez en cuando la mirada hacia nuestro rico pasado.

\section{BIBLIOGRAFÍA}

1) Lastres J. Historia de la Medicina Peruana Tomo II y III. Lima: UNMSM; 1951

2) Barreda y Laos, Felipe. Vida Incelectual de la Colonia. Lima: Ed. San Martín; 1909.

3) Eguiguren LA. Alma Mater. UNMSM; Lima: 1939.

4) Eguiguren LA. Diccionario Histórico cronológico de la Universidad Real y pontificia de San Marcos. Lima: Eguiguren, edición personal; 1940.

5) Mendiburu M. Diccionario Histórico Biográfico del Perú. Lima: Imp. Gij; 1936.

6) Valdizán H. La Facultad de Medicina de Lima. Lima: Imp. Americana; 1925

7) Valdizán H. Diccionario de la Medicina Peruana. Lima: Imp. Asilo Larco Herrera: 1923. 